CLINICAL STUDY

\title{
The capability of plasma osteoprotegerin as a predictor of cardiovascular disease: a systematic literature review
}

\author{
Mads Nybo and Lars M Rasmussen \\ Department of Biochemistry, Pharmacology and Genetics, Odense University Hospital, Sdr. Boulevard 29, DK-5000 Odense, Denmark \\ (Correspondence should be addressed to M Nybo; Email: mads.nybo@ouh.regionsyddanmark.dk)
}

\begin{abstract}
Objective: Osteoprotegerin (OPG) strongly inhibits bone resorption and may also serve as a vascular calcification inhibitor. However, recent studies have indicated that high plasma OPG is a strong predictor of cardiovascular disease (CVD) and mortality. To evaluate this capability, the data concerning OPG as a CVD predictor was gathered through a systematic literature review.

Design and methods: Studies investigating OPG as a predictor of CVD or mortality were extracted from Medline and the Cochrane Library, retrieving 187 articles. Non-relevant articles were excluded, resulting in a total of 45 articles. After thorough evaluation of the abstracts, only eight prospective studies containing a follow-up period with a clinical emphasis on CVD were eligible for the literature review.

Results: All studies except one confirmed that OPG measurement adds important prognostic information to the existing markers of CVD and mortality in high-risk populations. Hazard ratios emphasized the significant correlation between plasma OPG concentration and mortality. Due to methodological problems (e.g., population investigated, measurement principle, and statistics performed), meta-analysis could not be performed. As only one study was conducted in a healthy cohort, the results cannot per se be extrapolated to the general population.

Conclusion: The combined results support plasma OPG as an independent predictor of CVD and mortality in high-risk populations. However, more longitudinal studies in general cohorts are needed before the use of plasma OPG can be evaluated in this regard.
\end{abstract}

European Journal of Endocrinology 159 603-608

\section{Introduction}

Osteoprotegerin (OPG) is a glycoprotein first described in 1997 by Simonet et al. (1), who named the protein due to its apparent capacity to protect bone. It is produced in many different tissues, including bone, vasculature (2), heart, lung, kidney, and placenta (1), and also circulates in plasma, although the concentration here is much lower than in bone and arterial tissue $(3,4)$. At present, there is no information about the predominant source of the circulating OPG. Studies have, however, identified vascular smooth muscle cells (VSMC) as a potential main arterial source of OPG, which can be released by, for example, heparin (5). The route of elimination for the molecule is unknown, but a decline in kidney function has been found associated with increasing OPG levels (6).

OPG serves as a soluble decoy receptor for two members of the tumor necrosis factor receptor superfamily: TNFSF11 and TNFSF10. As TNFSF11 stimulates bone resorption through induction of osteoclast differentiation and activation, the neutralization of TNFSF11 by OPG prevents bone resorption and bone loss. Consistently, OPG knockout mice have severe bone loss and multiple osteoporotic fractures (7). This principle has recently inspired a new osteoporosis drug, denosumab, which is a
MAB directed against TNFSF11. In addition, the majority of the OPG-deficient mice also develop medial calcifications of the renal arteries and the aorta (7). Although it is still unclear whether these observations are secondary to severe osteoporosis in the knockout mice, the results initiated the idea of $\mathrm{OPG}$ as an inhibitor of vascular calcifications. Despite the high amounts of OPG found in the arterial wall and produced in VSMC, the exact function of OPG remains unknown. Somewhat in contrast to the idea of OPG as a vascular calcification inhibitor and therefore a protector of the arterial wall, a series of outcome studies have recently indicated that plasma OPG is a strong predictor of cardiovascular disease (CVD). Many studies have in a cross-sectional manner investigated the significance of OPG levels compared with known risk factors. Our initial aim was therefore to make a formal integration of the various studies in a meta-analysis. Unfortunately, the studies retrieved were so heterogeneous of design and composition that such type of analysis was not possible. Instead, a systematic literature review was conducted to gather the data from the prospective studies of OPG and prediction of CVD, and furthermore to see whether this is applicable to all populations. 


\section{Materials and methods}

\section{Search strategy}

Studies investigating plasma OPG in humans were extracted from Medline and the Cochrane Library. The search period ended in March 2008. Both investigators took part in selection of the articles. The search strategy for PubMed was: "Outcome Assessment (Health Care)'(MeSH) AND 'OPG'(MeSH) OR 'CVDs/blood' (MeSH) AND 'OPG'(MeSH; limits: English, human) OR 'OPG'(MeSH Major Topic; limits: English, human)'. For all MeSH word searches, all subheadings and all attached MeSH word terms were included in the search (i.e., an exploded search). The search strategy for the Cochrane Library was: 'OPG OR OPG AND MeSH descriptor CVD explode all trees OR MeSH descriptor Death AND Fatal outcome explode all trees'.

\section{Evaluation of articles}

The focus of the articles along with the materials and methods used were evaluated in order to further extract the relevant articles for this survey. As shown in Fig. 1,

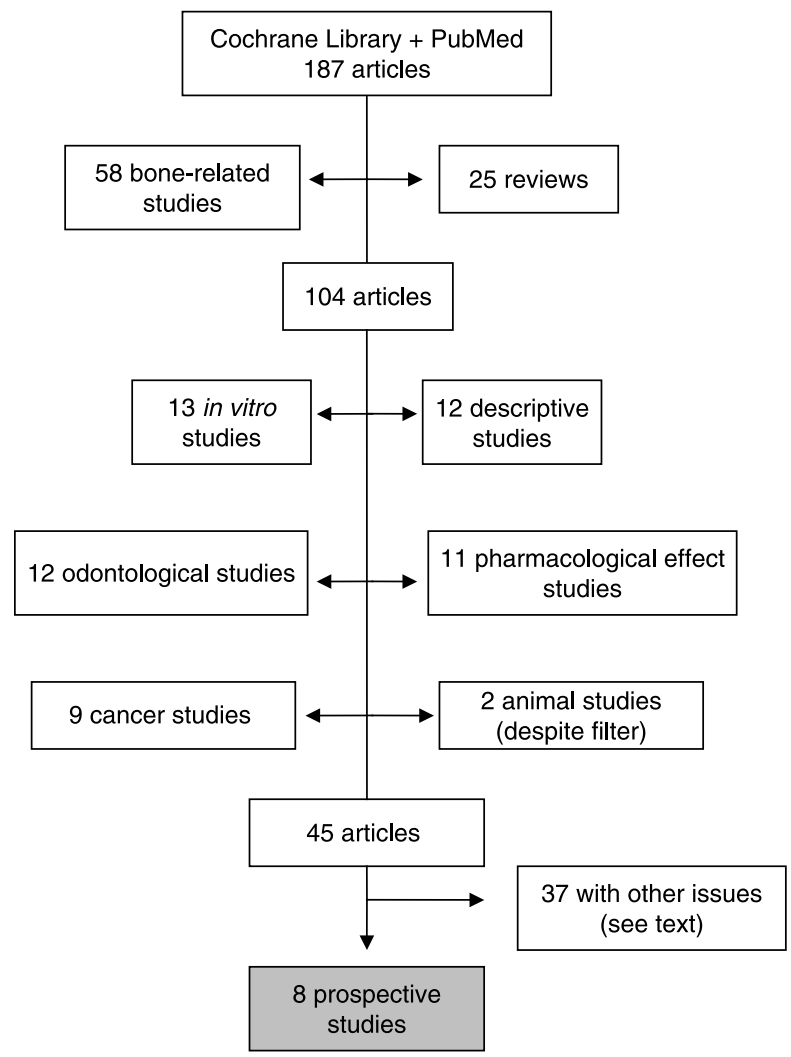

Figure 1 Flowchart of retrieved, excluded, and analyzed articles. Only 8 of the 187 retrieved papers fulfilled the criteria for a prospective study of OPG and CVD. Papers sorted out included cross-sectional studies (OPG concentrations in different populations) or studies concerning OPG or TNFSF11 assays. articles selected mainly consisted of bone-related studies, while other areas investigated included in vitro studies, odontology, and pharmaceutical aspects. The remaining articles were thoroughly read by both authors, extracting the papers fulfilling the following criteria: a prospective study of a well defined cohort with concise defined cardiovascular end points or mortality, and with a statistical evaluation of the correlation between these events and the measured OPG concentrations.

\section{Results}

The search resulted in retrieval of 187 articles. The amount of articles was diminished from the initial 187 to 45 as described in Materials and methods. Following the selection criteria described, a total of eight articles were at the end eligible for the review. The studies identified were heterogeneous in many aspects, including the population investigated, the outcome parameter and the OPG measurement technique as summarized in Table 1.

\section{Summary of prospective studies retrieved}

Browner 2001 (8) In this epidemiological study following 490 elderly women (<65 years) for 10 years, serum OPG concentrations were $30 \%$ higher in women with diabetes than in non-diabetic women. The relative risk of cardiovascular mortality was more than fourfold higher in the group with the highest quintile of serum OPG concentrations when adjusted for age, diabetes, hypertension, education, hormone replacement treatment, smoking, body mass index (BMI), lipids, and C-reactive protein (CRP).

Kiechl 2004 (9) Severity, initiation, and progression of atherosclerosis in the carotid arteries were assessed in a population-based study. Incident CVD and vascular mortality were recorded over a 10-year period. In multivariate analyses (adjusted for age, gender, diabetes, hypertension, social class, smoking, BMI, lipids, fibrinogen, diff. count, and ferritin), serum OPG remained significantly related to severity and 10-year progression of carotid atherosclerosis. Furthermore, a high level of serum OPG was an independent risk factor for incident CVD and vascular mortality, but not for mortality due to non-vascular causes.

Ueland 2004 (10) A total of 234 patients with acute myocardial infarction (AMI) complicated with heart failure were followed for 27 months and adverse outcome during follow-up was noted. For hazard ratio (HR) assessment, the highest quartile was compared with the lowest after adjustment for age, diabetes, hypertension, smoking, creatinine clearance, prior AMI, and N-terminal pro-B-type natriuretic peptide. Elevated 
Table 1 Prospective studies concerning osteoprotegerin (OPG) in a summarized form.

\begin{tabular}{|c|c|c|c|c|c|c|}
\hline & Study population (age) & $\begin{array}{l}\text { Follow-up } \\
\text { time }\end{array}$ & $\begin{array}{l}\text { Outcome } \\
\text { parameter }\end{array}$ & $N$ & Hazard ratio & Matrix/OPG assay \\
\hline Browner et al. 2001 (8) & $\begin{array}{l}\text { Ambulatory women } \\
>65 \text { years }(72 \text { years } \pm 5)\end{array}$ & 10 years & CV mortality & 490 & $1.3(1.0-1.6)$ & Serum/Amgen Inc. \\
\hline Kiechl et al. 2004 (9) & $\begin{array}{l}\text { General population } \\
\quad(59 \text { years } \pm 9.9)\end{array}$ & 10 years & $\begin{array}{l}\text { CVD and CV } \\
\text { mortality }\end{array}$ & 915 & $3.1(1.2-2.8)$ & Serum/R\&D Systems \\
\hline Ueland et al. 2004 (10) & $\begin{array}{l}\text { HF patients post-AMI } \\
(67.8 \text { years } \pm 9.8)\end{array}$ & 2 years & $\begin{array}{l}\text { CV events and } \\
\text { mortality }\end{array}$ & 243 & $11.2(1.5-85.4)$ & Plasma/R\&D Systems \\
\hline Morena et al. 2006 (11) & $\begin{array}{l}\text { Hemodialysis patients } \\
\text { (Median } 66.7 \text { years) }\end{array}$ & 2 years & $\begin{array}{l}\text { All-cause and } \\
\text { CV mortality }\end{array}$ & 185 & $\begin{array}{l}2.5(0.9-7.1) \\
\quad 5.7(1.4-22.7)\end{array}$ & Plasma/Biovendor \\
\hline Anand et al. 2006 (12) & $\begin{array}{l}\text { Diabetic patients without } \\
\text { CV symptoms } \\
(52.7 \text { years } \pm 8.4)\end{array}$ & 18 months & CV events & 510 & NA & Plasma/Biomedica \\
\hline Hjelmesaeth et al. 2006 (13) & $\begin{array}{l}\text { Renal transplantation } \\
\quad(47 \text { years } \pm 16)\end{array}$ & 8 years & $\begin{array}{l}\text { All-cause and } \\
\text { CV mortality }\end{array}$ & 172 & $\begin{array}{l}6.0(3.1-11.6) \\
\quad 8.2(2.5-26.4)\end{array}$ & Serum/R\&D Systems \\
\hline Anand et al. 2007 (14) & $\begin{array}{l}\text { Type } 2 \text { diabetics } \\
\quad(52 \text { years } \pm 8)\end{array}$ & 2.5 years & $\mathrm{CAC}$ & 398 & NA & Plasma/Biomedica \\
\hline Omland et al. 2008 (15) & $\begin{array}{l}\text { Acute coronary syndrome } \\
(66 \text { years } \pm 9)\end{array}$ & 89 months & $\begin{array}{l}\text { CV events and } \\
\text { mortality }\end{array}$ & 897 & $1.4(1.2-1.7)$ & Plasma/R\&D Systems \\
\hline
\end{tabular}

NA, not available.

plasma OPG at baseline was found associated with adverse outcome and remained an independent prognostic indicator after adjustment for other known predictors of $\mathrm{CV}$ events and mortality.

Morena 2006 (11) This study investigated the contribution of OPG, TNFSF11, and mineral metabolism disorders to outcome in hemodialysis patients. Out of 185 hemodialysis patients followed prospectively for 2 years, 50 patients died (27 from CVD). Elevated plasma OPG predicted all-cause and CV mortality when adjusted for age, gender, dialysis vintage, diabetes, hypertension, and smoking. The association of plasma OPG with all-cause mortality was stronger in patients with $\mathrm{CRP} \geq 12.52 \mathrm{mg} / \mathrm{l}$.

Anand 2006 (12) In this study, 510 type 2 diabetic patients free of $\mathrm{CV}$ symptoms were evaluated by imaging of coronary arterial calcification (CAC) and markers such as hsCRP, IL-6, and plasma OPG. Patients were followed for $18 \pm 5$ months. Plasma OPG was significantly elevated in patients with increased CAC and remained strongly associated with elevated CAC scores after adjustment for age, gender, and other risk factors. During follow-up, $16 \mathrm{CV}$ events occurred, but in a multivariate model, CAC score was the only independent predictor of adverse events. Of the biomarkers studied, only plasma OPG predicted sub-clinical disease and near-term CV events. Cox plot for event-free survival showed a risk ratio of $5.76(1.28-26)$ in the highest tertile compared with the lowest. Multivariate analysis was not performed.

Hjelmesaeth 2006 (13) A total of 172 consecutive renal transplant recipients without diabetes were followed for 8 years. Mortality and CV death were compared with different markers, e.g., OPG (several weeks after transplantation). Patients with serum OPG levels in the upper quartile had significantly higher allcause mortality and CV death, and Cox regression analysis showed that high serum OPG levels remained an independent predictor of all-cause mortality and CV death. Multiple linear regression analysis revealed that age, creatinine clearance, and hsCRP all were independently associated with serum OPG.

Anand 2007 (14) With a mean follow-up of $2.5 \pm 0.4$ years, 398 type 2 diabetic subjects without prior coronary disease or symptoms (age $52 \pm 8$ years) were evaluated serially by CAC imaging. Potential markers, including serum hsCRP, IL-6, and plasma OPG levels, were measured at baseline and at follow-up. Age, male gender, hypertension, baseline $\mathrm{CAC}, \mathrm{HbAlc}>7$, waisthip ratio, IL-6, OPG, use of $\beta$-blockers, calcium channel antagonists, angiotensin converting enzyme (ACE) inhibitors, statins, and Framingham/UKPDS (United Kingdom Prospective Diabetes Study) risk scores were univariable predictors of CAC progression. In the multivariate model, only baseline $\mathrm{CAC}, \mathrm{HbA} 1 \mathrm{c}$, and use of statins were independent predictors of CAC progression.

Omland 2008 (15) Serum OPG was measured in 897 patients with acute coronary syndrome $(71 \%$ men) and related to the incidence of death, heart failure hospitalizations, myocardial infarction, and stroke. A total of 261 patients died during a median followup of 89 months. Baseline OPG concentrations were strongly associated with increased long-term mortality, but weaker with recurrent MI. After adjustment for conventional risk markers (Troponin I, CRP, B-type natriuretic peptide, and ejection fraction), the association remained significant for mortality. 


\section{Discussion}

This systematic literature review was conducted to clarify the evidence for OPG as a predictor of CVD and mortality. As mentioned, the initial scope was to make a formal integration of the various studies in a meta-analysis, but as the studies retrieved were so heterogeneous of design and composition such a thorough analysis was not possible. Eight prospective studies were found and, as summarized in Table 1, all studies except one indicate that OPG measurement does add important prognostic information to the existing markers of CVD and mortality. However, the one study that did not find OPG as an independent predictor only investigated $\mathrm{CAC}$ as an end point (14), and the study can therefore not be credited for information concerning prediction of CVD and/or mortality as such. The authors of this study also published a similar study, but as the design was very different in the two studies (different score system, participants were further selected), a sheer comparison between the two studies was difficult. Of note, only one of all the studies was conducted in an apparently healthy cohort (9), and the results, in general, can therefore not per se be extrapolated to a random population. Despite the clear overweight of studies in favor of OPG as an independent CVD predictor, some of the following methodological problems need consideration.

\section{Population issues}

The cohorts in the retrieved studies differed in many ways, as some investigations were part of a diabetes study, while others were a population-based study, the information concerning the participants differed considerably and were not comparable. Also, some populations were followed for 10 years, while others only had a follow-up period of 18 months. Furthermore, age differed considerably varying from a mean of $47( \pm 16)$ to $72( \pm 5)$ years. This is important as OPG concentrations have been shown to keep a stable level until the age of 60 and 70 years in women and men respectively, after which it increases in both genders (16). The distribution between genders and the difference in age therefore represents a factor of uncertainty in this comparison.

\section{Analytical issues}

As shown in Table 1, OPG measurements were conducted with many different kits, and assays were constructed differently with use of different antibodies and calibrators. The reported mean OPG concentrations ranged from 220 to $3000 \mathrm{pg} / \mathrm{ml}$, which could be due to analytical aspects, especially concerning calibration of the different assay kits, but it could also reflect differences in the inclusion criteria used. Furthermore, some studies were based on serum OPG measurements, while others measured plasma OPG. As OPG behaves differently in those two matrices (17), results cannot be directly compared. Also, pre-analytical issues affecting the OPG concentration in samples such as enzymatic degradation, freeze-thaw and binding to other proteins still need thorough investigation to assure a correct and comparable measurement.

\section{Statistical issues}

Some of the studies did not apply multivariate analyses, so differences found could be due to other variables affecting the OPG concentration. Furthermore, the five studies using multiple regression analysis did not include identical risk factors, so, for example, some calculations could have included kidney function, CVD history, and acute phase reactants while others did not. As far as kidney function is concerned, this is important as previous studies have shown high correlations between serum OPG concentrations and creatinine (6). The HRs reported emphasize the independent correlation between the OPG concentration and mortality with an overall HR between 1.3 and 11.2 for the highest quartiles in some studies, but the variance within each study was enormous. Unfortunately, none of the studies made a direct comparison of OPG with known biochemical risk markers to demonstrate a potential gain of predictive power, for example, by the comparison of receiver operating characteristics curves.

\section{OPG in the arterial wall}

High amounts of OPG is present in the arterial wall, and the concentration in extracts of human aorta has been found to be at least as high as in bone extracts and 1000 times higher than the plasma concentration (4). The molecule is distributed widely throughout the layers of the vessel wall, both in non-diseased and atherosclerotic areas $(4,18)$. Also, the ligands of OPG, TNFSF11, and TNFSF10 are present in the vasculature, as demonstrated immunologically in both rodent (19) and human arteries (20), although the expression level is lower than OPG. Most OPG in the vasculature is believed to derive locally, since vascular cells produce OPG. Several studies have shown that VSMC produce very high amounts of the molecule and that the production can be regulated by several factors like tumor necrosis factor- $\alpha$, IL-1, and insulin. In addition, induction of calcifications in VSMC in vitro downregulates OPG expression. Endothelial cells do also produce OPG, however, in quiescent states at much lower rates (5). With very high OPG concentrations in the normal arterial wall, it is likely that the level of OPG in plasma to some degree reflect arterial content. It is moreover plausible that increased circulating levels may reflect injuries to the arterial wall, as for example seen in diabetes and in situations with widespread vascular calcifications $(4,20)$, putatively as a result of the influence of pro-inflammatory molecules on arterial cells. 


\section{Relations to vascular calcifications and atherosclerosis}

Not much is known about the functions of OPG in the arterial wall. Effects of OPG and its ligands have not been defined in VSMC, although it has been shown that OPG may act as a survival factor in endothelial cells. As mentioned, OPG is considered an inhibitor of vascular calcifications based on the observations by Bucay that OPG knockout mice develop vascular calcifications (7). This observation has been confirmed and extended by Orita et al., showing that the calcifications were exacerbated after feeding the animals with vitamin-D and phosphorus (21). Also, it has been shown that the calcifications could be reduced, when osteoprotegerin was reintroduced by transgenic expression in the liver (19). Of note, severe osteoporosis is known to induce arterial calcifications per se, probably initiated by circulating bone degradation products, and therefore it is important to acknowledge that a large part of the calcifications displayed in OPG knockout mice may be due to secondary effects (22).

A potential link between OPG and atherosclerosis has been studied in OPG knockout mice crossed with ApoE knockout mice, a well-known atherosclerosis model. Increased amounts of atherosclerosis were seen in the double knockout mice, indicating that OPG acts as an inhibitor of atherogenesis (23). Interpretation of the results is again hampered by the effect of osteoporosis in the $\mathrm{OPG}^{-/-}$mice. In other experiments, exogenously injected OPG did not alter the amount of atherosclerosis in $\mathrm{ApoE}^{-/-}$mice (24), but interestingly injections of TNFSF10 in a model of atherosclerosis in animals with diabetes displayed augmented plaque development, maybe due to induction of apoptosis in cells participating in the build-up of the atherosclerotic plaque (25). Thus, although the studies presented here indicate that the level of circulating OPG may serve as a potential marker of CVD risk, the roles of the molecule and its ligands in the arterial wall, especially in relation to atherosclerosis and calcifications are still not clear.

\section{Perspectives}

Plasma OPG is emerging as a strong and independent predictor of CVD in some situations. However, in order to better understand the significance of high plasma OPG concentrations, we need to understand more about the biology of the molecule in the arterial wall and more about the interaction of OPG with its ligands TNFSF11 and TNFSF10. Combined with prospective studies in different settings, especially in a healthy cohort, it will be possible to determine the capability of OPG as a CVD risk marker in a random population and, moreover, to understand whether functions related to OPG or its ligand may be targets for future interventions. Furthermore, studies of the influence of pharmacological treatment on OPG concentrations may give useful information regarding OPG as a putative CVD monitor. A few studies have tried to elucidate this (26), but further studies in different populations treated with different pharmaceutical products are needed.

\section{Conclusion}

Evidence is gathering that plasma OPG concentrations are an important, independent predictor of $\mathrm{CV}$ mortality, at least in high-risk populations. Unfortunately, there are many methodological problems in aligning the studies assembled here, and a formal metaanalysis can therefore not be provided. Moreover, longitudinal studies in the general populations are needed before the use of plasma OPG can be evaluated in that context.

\section{References}

1 Simonet WS, Lacey DL, Dunstan CR, Kelley M, Chang MS, Lüthy R, Nguyen HQ, Wooden S, Bennett L, Boone T, Shimamoto G, DeRose M, Elliott R, Colombero A, Tan HL, Trail G, Sullivan J, Davy E, Bucay N, Renshaw-Gegg L, Hughes TM, Hill D, Pattison W, Campbell P, Sander S, Van G, Tarpley J, Derby P, Lee R \& Boyle WJ. Osteoprotegerin: a novel secreted protein involved in the regulation of bone density. Cell 199789 309-319.

2 Collin-Osdoby P, Rothe L, Anderson F, Nelson M, Maloney W \& Osdoby P. Receptor activator of NF- $\kappa$ B and osteoprotegerin expression by human microvascular endothelial cells, regulation by inflammatory cytokines, and role in human osteoclastogenesis. Journal of Biological Chemistry 2001276 20659-20672.

3 Ueland T, Brixen K, Mosekilde L, Mosekilde L, Flyvbjerg A \& Bollerslev J. Age-related changes in cortical bone content of insulin-like growth factor binding protein (IGFBP)-3, IGFBP-5, osteoprotegerin, and calcium in postmenopausal osteoporosis: a cross-sectional study. Journal of Clinical Endocrinology and Metabolism $2003 \mathbf{8 8} 1014-1018$.

4 Olesen P, Ledet T \& Rasmussen LM. Arterial osteoprotegerin: increased amounts in diabetes and modifiable synthesis from vascular smooth muscle cells by insulin and TNF- $\alpha$. Diabetologia $2005 \mathbf{4 8} 561-568$.

5 Nybo M \& Rasmussen LM. Heparin releases osteoprotegerin from vascular cells in vitro and in vivo. Atherosclerosis, 2008 (doi: 10.1016/j.atherosclerosis.2008.03.026).

6 Rasmussen LM, Tarnow L, Hansen TK, Parving HH \& Flyvbjerg A. Plasma osteoprotegerin levels are associated with glycaemic status, systolic blood pressure, kidney function and cardiovascular morbidity in type 1 diabetic patients. European Journal of Endocrinology $2006 \mathbf{1 5 4} 75-81$.

7 Bucay N, Sarosi I, Dunstan CR, Morony S, Tarpley J, Capparelli C, Scully S, Tan HL, Xu W, Lacey DL, Boyle WJ \& Simonet WS. Osteoprotegerin-deficient mice develop early onset osteoporosis and arterial calcification. Genes and Development 199812 $1260-1268$

8 Browner WS, Lui LY \& Cummings SR. Associations of serum osteoprotegerin levels with diabetes, stroke, bone density, fractures, and mortality in elderly women. Journal of Clinical Endocrinology and Metabolism 200186 631-637.

9 Kiechl S, Schett G, Wenning G, Redlich K, Oberhollenzer M, Mayr A, Santer P, Smolen J, Poewe W \& Willeit J. Osteoprotegerin is a risk factor for progressive atherosclerosis and cardiovascular disease. Circulation $20041092175-2180$.

10 Ueland T, Jemtland R, Godang K, Kjekshus J, Hognestad A, Omland T, Squire IB, Gullestad L, Bollerslev J, Dickstein K \& 
Aukrust P. Prognostic value of osteoprotegerin in heart failure after acute myocardial infarction. Journal of the American College of Cardiology 200444 1970-1976.

11 Morena M, Terrier N, Jaussent I, Leray-Moragues H, Chalabi L, Rivory JP, Maurice F, Delcourt C, Cristol JP, Canaud B \& Dupuy AM. Plasma osteoprotegerin is associated with mortality in hemodialysis patients. Journal of the American Society of Nephrology 2006 $17262-270$.

12 Anand DV, Lahiri A, Lim E, Hopkins D \& Corder R. The relationship between plasma osteoprotegerin levels and coronary artery calcification in uncomplicated type 2 diabetic subjects. Journal of the American College of Cardiology 200647 1850-1857.

13 Hjelmesaeth J, Ueland T, Flyvbjerg A, Bollerslev J, Leivestad T, Jenssen T, Hansen TK, Thiel S, Sagedal S, Roislien J \& Hartmann A. Early posttransplant serum osteoprotegerin levels predict longterm (8-year) patient survival and cardiovascular death in renal transplant patients. Journal of the American Society of Nephrology $2006171746-1754$.

14 Anand DV, Lim E, Darko D, Bassett P, Hopkins D, Lipkin D, Corder R \& Lahiri A. Determinants of progression of coronary artery calcification in type 2 diabetes role of glycemic control and inflammatory/vascular calcification markers. Journal of the American College of Cardiology $2007502218-2225$.

15 Omland T, Ueland T, Jansson AM, Persson A, Karlsson T, Smith C, Herlitz J, Aukrust P, Hartford M \& Caidahl K. Circulating osteoprotegerin levels and long-term prognosis in patients with acute coronary syndromes. Journal of the American College of Cardiology $2008 \mathbf{5 1} 627-633$.

16 Kudlacek S, Schneider B, Woloszcuk W, Pietchmann P \& Willvonseder R. Serum levels of osteoprotegerin increase with age in a healthy adult population. Bone 200332 681-686.

17 Chan BY, Buckley KA, Durham BH, Gallagher JA \& Fraser WD. Effect of anticoagulants and storage temperature on the stability of receptor activator for nuclear factor-kappa $B$ ligand and osteoprotegerin in plasma and serum. Clinical Chemistry 2003 49 2083-2085.

18 Tyson KL, Reynolds JL, McNair R, Zhang Q, Weissberg PL \& Shanahan CM. Osteo/chondrocytic transcription factors and their target genes exhibit distinct patterns of expression in human arterial calcification. Arteriosclerosis, Thrombosis, and Vascular Biology 200323 489-494.
19 Min H, Morony S, Sarosi I, Dunstan CR, Capparelli C, Scully S, Van G, Kaufman S, Kostenuik PJ, Lacey DL, Boyle WJ \& Simonet WS. Osteoprotegerin reverses osteoporosis by inhibiting endosteal osteoclasts and prevents vascular calcification by blocking a process resembling osteoclastogenesis. Journal of Experimental Medicine 2000192 463-474.

20 Schoppet M, Al-Fakhri N, Franke FE, Katz N, Barth PJ, Maisch B, Preissner KT \& Hofbauer LC. Localization of osteoprotegerin, tumor necrosis factor-related apoptosis-inducing ligand, and receptor activator of nuclear factor-kappaB ligand in Mönckeberg's sclerosis and atherosclerosis. Journal of Clinical Endocrinology and Metabolism 200489 4104-4112.

21 Orita Y, Yamamoto H, Kohno N, Sugihara M, Honda H, Kawamata S, Mito S, Soe NN \& Yoshizumi M. Role of osteoprotegerin in arterial calcification: development of new animal model. Arteriosclerosis, Thrombosis, and Vascular Biology 200727 2058-2064.

22 Price PA, Faus SA \& Williamson MK. Warfarin-induced artery calcification is accelerated by growth and vitamin D. Arteriosclerosis, Thrombosis, and Vascular Biology 200020 317-327.

23 Bennett BJ, Scatena M, Kirk EA, Rattazzi M, Varon RM, Averill M, Schwartz SM, Giachelli CM \& Rosenfeld ME. Osteoprotegerin inactivation accelerates advanced atherosclerotic lesion progression and calcification in older ApoE - / - mice. Arteriosclerosis, Thrombosis, and Vascular Biology 200626 2117-2124.

24 Morony S, Tintut Y, Zhang Z, Cattley RC, Van G, Dwyer D, Stolina M, Kostenuik PJ \& Demer LL. Osteoprotegerin inhibits vascular calcification without affecting atherosclerosis in $\operatorname{ldlr}(-/-)$ mice. Circulation $2008 \mathbf{1 1 7} 411-420$.

25 Secchiero P, Candido R, Corallini F, Zacchigna S, Toffoli B, Rimondi E, Fabris B, Giacca M \& Zauli G. Systemic tumor necrosis factor-related apoptosis-inducing ligand delivery shows antiatherosclerotic activity in apolipoprotein E-null diabetic mice. Circulation $20061141522-1530$.

26 Nellemann B, Gormsen LC, Dollerup J, Schmitz O, Mogensen CE, Rasmussen LM \& Nielsen S. Simvastatin reduces plasma osteoprotegerin in type 2 diabetic patients with microalbuminuria. Diabetes Care 200730 3122-3124.

Received 14 July 2008

Accepted 16 July 2008 